\section{Crusted scabies in patients with long-term use of oral corticosteroid with different underlying diseases - case series}

\author{
Cut Shelma Maharani, Densy Violina \\ Harnanti, Hasnikmah Mappamasing, \\ Septiana Widyantari, Sawitri, \\ Evy Ervianty, Dwi Murtiastutik, \\ Sunarko Martodihardjo, \\ M. Yulianto Listiawan \\ Department of Dermatology \\ Venereology, Faculty of Medicine \\ Airlangga University, Dr Soetomo \\ General Hospital, Surabaya, Indonesia
}

\begin{abstract}
People with a weakened immune system may develop the severe form of scabies called crusted scabies. We have two cases of female patients with history of using longterm oral corticosteroid and then developing scabies infection. The first patient had other comorbidities which caused her become more susceptible while the second patient had been diagnosed with bullous pemphigoid. Both patients complained thick crust on some parts of their bodies, accompanied with itchy papules. Based on microscopic examination from lesion scraping, we found the adult form of sarcoptes scabiei and crusted scabies diagnosis was established. The lesions were improving when they got combination of topical sulfur precipitate, salicylic acid, and permethrine $5 \%$. Crusted scabies is characterized by hyperkeratosis and crusting of the skin due to the profuse proliferation of mites resulting from an altered host response. Combination of topical antiscabies and keratolytic can make the crusts thinner and improve topical absorption.
\end{abstract}

\section{Introduction}

Scabies is a disease caused by Sarcoptes scabiei var. hominis parasite infestation, family Sarcoptidae, class Arachnida on the skin. Scabies is worldwide and affects all ages, races and socioeconomic levels. This disease is one of the major skin-health problems in developing countries and is associated with poverty and crowded environments. The estimated prevalence ranges from 0.2 to 71 percent, with as many as 100 million people affected worldwide. ${ }^{1}$ Transmission of scabies is usually from person to person by direct contact. There have been many authenticated instances in which scabies was contracted by wearing or handling heavily contaminated clothing, or by sleeping in an unchanged bed recently occupied by an infested individual. ${ }^{2}$ Transmission through clothing or linens is more likely with higher parasite burdens as seen in crusted (Norwegian) scabies. ${ }^{3}$

Clinical symptoms for the typical infestation of scabies include itching, especially at nighttime, accompanied by papular skin eruptions. Pathognomonic lesion in scabies infection is a burrow, which is a thin, thread-like, linear structure $1-10 \mathrm{~mm}$ in length. It is actually a tunnel caused by the movement of the mite in the stratum corneum, with a predilection for interdigital webs and the periumbilical and genital areas. $^{2}$

People with a weakened immune system (including those with HIV infection, lymphoma, or other conditions such as patients in immunosuppressive therapy) may develop the severe form of scabies called crusted scabies or Norwegian scabies. ${ }^{4}$ Crusted scabies begins with poorly defined erythematous patches that quickly develop prominent scales. Scales become warty, especially over bony prominences, then crusts and fissures can appear. The lesions are malodorous. Crusts and scales are teeming with mites that number in the hundreds of thousands. ${ }^{5}$ This uncommon and hyperkeratotic type of scabies infection tends to affect immunocompromised persons due to the lack of their immune system's ability to cope with the mite. ${ }^{6}$ Difficulty in treating Norwegian scabies frequently occurs because the thick crusts inhibit the penetration of topical antiscabies agent. Moreover, the sheer numbers of the mite also mean that a longer duration of treatment is required.?

We report two cases of crusted scabies but with different underlying diseases. Both patients were consuming oral corticosteroid for a long-term period before they got scabies infection. The first case was a female patient who received a misdiagnosis of scabies with other diseases. She consumed methylprednisolone $16 \mathrm{mg}$ three times daily for seven months by herself without any clinical improvements. This patient also had other comorbidity such as anemia et causa internal hemorrhoid, thrombocytopenia, hepatitis B, hypoalbuminemia, and spondilo-arthropathy. The second case was a different female patient who had been diagnosed with bullous pemphigoid eight months before she complained about scabies infection. She routinely consumed methylprednisolone with an adjustment dose (tapering dose) based on clinical appearances. Both patients had a weakened
Correspondence: Cut Shelma Maharani, Department of Dermatology Venereology, Faculty of Medicine Airlangga University, Dr Soetomo General Hospital, J1. Prof. Dr. Moestopo 6-8, Surabaya 60285, Indonesia Tel. +62.818756882.

E-mail: shelmaharani@gmail.com

Key words: crusted scabies, oral corticosteroid, thick crust.

Contributions: CSM, DVH, EE, MYL conception of the work; CSM, DVH, data collection; CSM, DVH, data analysis and interpretation; CSM, DVH, drafting the articles; HM, SW, S, $\mathrm{DM}, \mathrm{SM}$, critical revision of the article; EE, MYL, final approval of the version to be publish.

Conflict of interests: The authors declare no potential conflict of interest.

Received for publication: 1 February 2019. Accepted for publication: 25 February 2019.

This work is licensed under a Creative Commons Attribution-NonCommercial 4.0 International License (CC BY-NC 4.0).

(C) Copyright C.S. Maharani et al., 2019

Licensee PAGEPress, Italy

Dermatology Reports 2019; 11(s1):8095

doi:10.4081/dr.2019.8095

immune system due to long-term use of oral corticosteroid; this made them susceptible to infection, including scabies and the severe form of scabies infestation known as crusted scabies.

\section{Case Report}

\section{Case \#1}

A thirty-eight-year-old female patient came to the emergency ward of Dr. Soetomo General Hospital Surabaya complaining of thick crusts on parts of her body, beginning around seven months previously. It was accompanied with pruritic papules eruption on almost her entire body. Firstly, there was some small papules over her webs of fingers accompanied with itchy sensation especially at night. Her son and husband had similar symptoms. She went to her general practitioner and got methylprednisolone $16 \mathrm{mg}$ three times daily. She also felt pain in her low back. It made it difficult to move and she took a bath only once a day. She continued taking methylprednisolone with same doses by herself for seven months. From clinical findings on trunk, armpits, abdominal, extremities, pubic and also buttocks regions there were 
hyperpigmentation macules, non-sharply marginated, multiple erythematous papules and some pustules (Figure 1a). There were also thick crusts, erosion, and fissures on her fingers, both legs, and armpits. A scraping test revealed that there was adult form of mites (Figure 1b). The patient was diagnosed with Crusted scabies, secondary infection, and other comorbidity like anemia due to internal hemorrhoid, thrombocytopenia, hepatitis B, hypoalbuminemia, and spondiloarthropathy. The patient was treated with permethrin 5\%, 2-4 zalf (sulfur precipitate and salicylic acid), ceftriaxone injection $1 \mathrm{~g}$ twice daily, PRC transfusion, albumin transfusion and tramadol injection. The progress of dermatology status was good.

\section{Case \#2}

A thirty-four-year-old female presented with a main complaint of yellowish thick crust on some parts of her body, accompanied by pruritic papules erupting on almost all of her body, starting two weeks previously. The first lesion was itchy papules on the web of fingers on both hands, which then spread to almost her entire body. There was history of household members with the same symptoms. She had history of suffering bullous pemphigoid and took daily oral methylprednisolone and dapsone (diaminodiphenyl sulfone) for eight months. Clinical manifestations showed multiple erythematous papules and pustules on almost of her body accompanied with some thick scales on her elbows, nipples, hands and buttocks (Figure 2a). There were no bullae or vesicles. A scraping examination from the lesion showed scabies mites (Figure 2b). This patient was treated with topical permethrin 5\%, repeated until two weeks later, combined with 2-4 zalf (sulfur precipitate and salicylic acid), cetirizine 10 mg tablet once daily, and also erythromycin $500 \mathrm{mg}$ four times daily for seven days. After three weeks of treatment there was improvement; the erythematous papules were decreased and there was no thick crust or pustules. The patient was still continuing to take her oral methylprednisolone and dapsone for the treatment of bullous pemphigoid.

\section{Discussion}

Crusted scabies is characterized by hyperkeratosis and crusting of the skin due to the profuse proliferation of mites resulting from an altered host response..$^{3,4}$ This disease was first described by Boeck and Danielssen among leprosy patients in Norway in $1848.4,7$ High risk groups for this infection include those who are taking systemic glucocorticoid therapy or using potent topical glucocorticoid therapy, organ transplant recipients, those with a mental or physical disability, those infected with HIV or human T-lymphotrophic virus-1, and also people with malignancy. ${ }^{8,9}$ This severe variant of scabies occurs as widespread hyperkeratotic crusted lesions, hence the name "crusted scabies" is preferred as the syn- onym of "Norwegian scabies"., 2,9

Crusted scabies typically develops in patients with a defective T-cell immune response or decreased cutaneous sensation and a reduced ability to mechanically debride the mites. Crusted scabies also develops in Australian aborigines with normal immunity. The reason for the occurrence of crusted scabies in this community is unclear. Certain studies have shown an association between scabies and HLA-A11. Hyperkeratosis of the skin, which is a prominent feature in crusted scabies, is probably related to increased levels of interleukin-4. Recent studies have shown that skin-homing cytotoxic T cells contribute to an imbalanced inflammatory response in the dermis of crusted scabies lesional skin. This, in combination with the lack of B cells, results in a failure of the skin immune system to mount an effective response, resulting in uncontrolled growth of the parasite. $^{3,4,6}$

According to the literature, management of crusted scabies takes time. Lindane $1 \%$ lotion used weekly for 6 weeks has been reported to give good results in some cases, as well as lindane used $2-3$ times within a $48-72$ hour period. Permethrin 5\% has also been described as giving good results in some cases, but with concomitant use of the keratolytic agent salicylic acid $6 \%{ }^{4}$ Other literature found that two doses of oral ivermectin - an antihelmintic agent which has excellent antiparasitic properties $200 \mu \mathrm{g} / \mathrm{kg}$ given within a one-week interval produced a very effective result. It might a

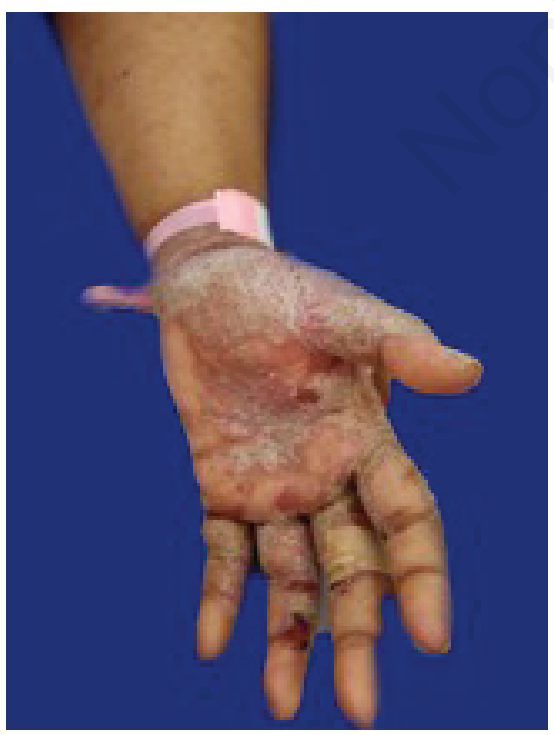

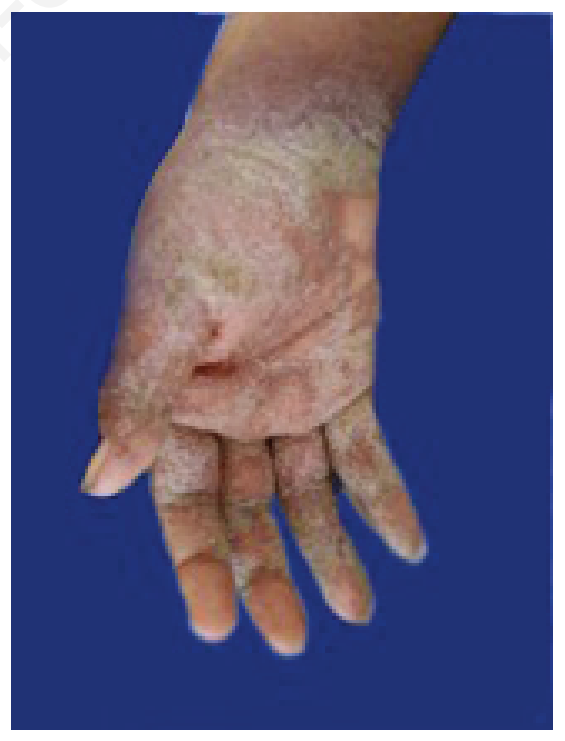

b

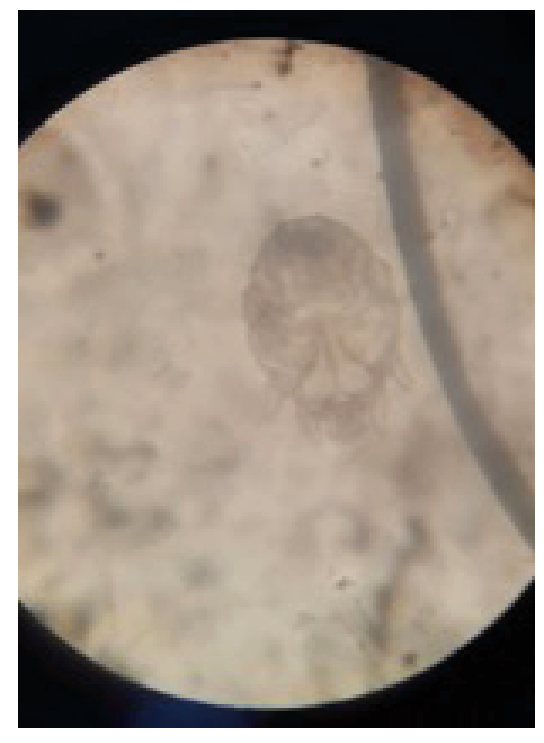

Figure 1. (a) Thick crust with some papules and minimal erosion on the first patient's palms. (b) Adult form of Sarcoptesscabei on microcopic examination from scrapping the lesion $(40 \mathrm{X})$. 
a

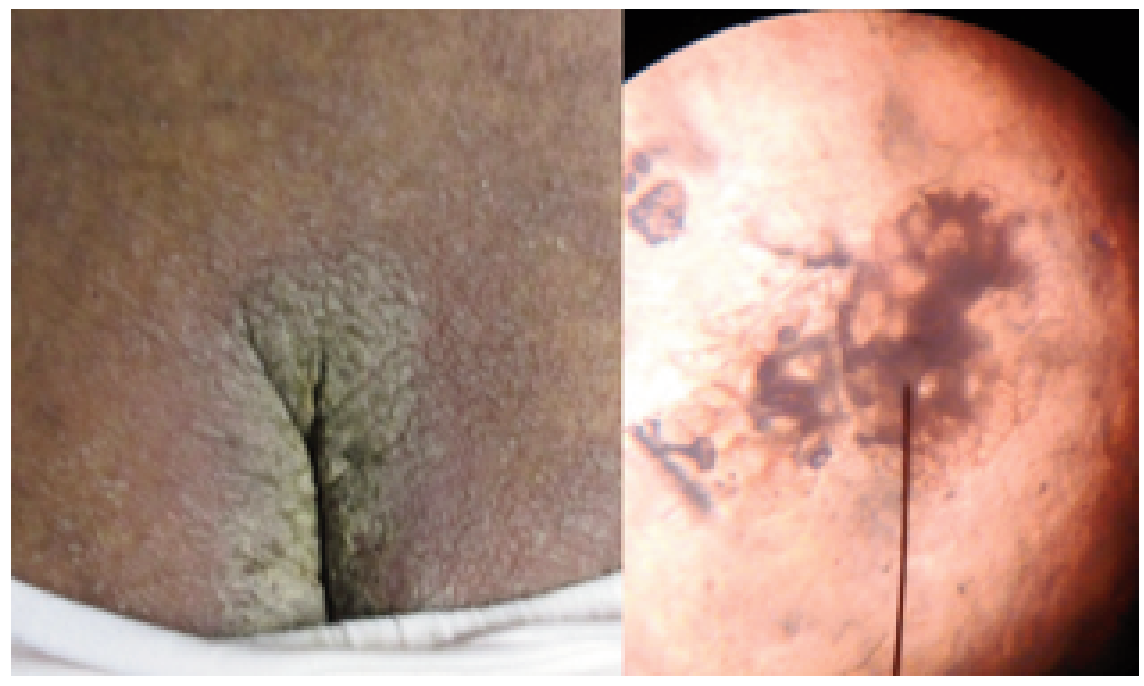

Figure 2. (a) Thick crust on the second patient's buttock accompany with erythematous papules. (b) Two adult form of Sarcoptesscabei (overlapping) on microcopic examination from scrapping the lesion $(40 \mathrm{X})$.

therefore be considered as a first line treatment for crusted scabies, with concomitant use of topical treatment. ${ }^{2,10,11}$ The combination of oral ivermectin and a topical scabicide is recommended as the oral medication cannot penetrate into the thickness of the keratinous debris.${ }^{10}$ This drug acts on nerve synapses utilizing glutamate or $\mathrm{y}$-aminobutyric acid. ${ }^{2}$ In this case, ivermectin was not used because there is no preparation available yet in our country. To reduce the thick crusts, the use of a keratolytic agent such as sulfur precipitate and salicylic acid can be used, and these agents can be found at 2-4 zalf. Permethrine 5\%, a topical antiscabies agent, was given to this patient, combined with the 2-4 zalf to make the crusts thinner so that topical absorption could improve.

\section{Conclusions}

Crusted scabies is a rare manifestation of scabies characterized by uncontrolled proliferation of mites in the skin. ${ }^{4}$ The immune system in the healthy host will reduce the mite load but rarely eliminates the mite. Long-term use of oral corticosteroid can cause failure of the immune system to suppress the proliferation of the mite.
This is an important cause of crusted scabies development., 4, 12 Management of crusted scabies takes a long time. ${ }^{2,10}$ In these cases we used 2-4 zalf (sulfur precipitate and salicylic acid) and permethrine 5\%, and obtained good results.

\section{References}

1. Romani, L., Steer, A.C., Whitfeld, M.J., Kaldor, J.M. Prevalence of scabies and impetigo worldwide: A systematic review. The Lancet Infectious Diseases 2015; doi:10.1016/S14733099(15)00132-2.

2. Burkhart, C.N., Burkhart, C.G. Scabies, other mites, and pediculosis, in: Goldsmith, L.A., Katz, S.I., Gilchrest, B.A., Paller, A.S., Leffell, D.J., Wolff, K (Ed.), Fitzpatrick's Dermatology in General Medicine 2012; McGraw-Hill, New York, pp. 2569-77.

3. Davis, J.S., McGloughlin, S., Tong, S.Y.C., Walton, S.F., Currie, B.J. A Novel Clinical Grading Scale to Guide the Management of Crusted Scabies. PLoS Neglected Tropical Diseases 7 2013; doi:10.1371/journal.pntd. 0002387

4. Karthikeyan, K. Crusted scabies. Indian journal of dermatology, venereology and leprology 2009; 75, 340-7. doi:10.4103/0378-6323.53128.

5. Binić, I., Janković, A., Jovanović, D., Ljubenović, M. Crusted (Norwegian) scabies following systemic and topical corticosteroid therapy. Journal of Korean Medical Science 2010; 25 , 188-191. doi:10.3346/jkms. 2010.25.1.188

6. Morgan, M.S., Arlian, L.G. Response of human skin equivalents to Sarcoptes scabiei. Journal of medical entomology 2010; 47, 877-83. doi:10.1603/ ME10012.

7. Walton, S.F., Currie, B.J. Problems in diagnosing scabies, a global disease in human and animal populations. Clinical Microbiology Reviews., 2007; doi:10.1128/CMR.00042-06.

8. Kartono, F., Lee, E.W., Lanum, D., Pham, L., Maibach, H.I. Crusted Norwegian scabies in an adult with langerhans cell histiocytosis: Mishaps leading to systemic chemotherapy. Archives of Dermatology 2007; 143, 626-628. doi:10.1001/ archderm.143.5.626.

9. Chan, C.C., Lin, S.J., Chan, Y.C., Liao, Y.H. Infestation by Norwegian scabies. CMAJ 2009; 181, 289. doi:10.1503/cmaj.081576

10. Chhaiya, S., Dave, J., Shah, H., Patel, V., Mehta, D. Comparative efficacy and safety of topical permethrin, topical ivermectin, and oral ivermectin in patients of uncomplicated scabies. Indian Journal of Dermatology, Venereology, and Leprology 2012; 78, 605. doi:10.4103/0378-6323.100571

11. Goldust, M., \& Rezaee, E. The efficacy of topical ivermectin versus malation $0.5 \%$ lotion for the treatment of scabies. The Journal of Dermatological Treatment 2013; https://doi.org/10.3109/09546634.2013. 782093

12. Roberts, L. J., Huffam, S. E., Walton, S. F., \& Currie, B. J. Crusted scabies: Clinical and immunological findings in seventy-eight patients and a review of the literature. Journal of Infection 2005; https://doi.org/10.1016/j.jinf.2004.08.0 33. 